\title{
Physical and Mechanical Properties of Turfy Soils under Confining and Axial Pressure Increases Stress Paths in Jilin Province, Northeast China
}

\author{
Yan Lv $\mathbb{D}^{1},{ }^{1}$ Yaolong Huang $\mathbb{D}^{2},{ }^{2}$ Chang Liu $\mathbb{D}^{1},{ }^{1}$ Zhandong Su $\mathbb{D}^{3},{ }^{3}$ and Lei Nie $\mathbb{D}^{1}$ \\ ${ }^{1}$ College of Construction Engineering, Jilin University, Changchun 130026, Jilin, China \\ ${ }^{2}$ Putian University, Putian 351100, Fujian, China \\ ${ }^{3}$ Institute of Disaster Prevention, Sanhe 065201, Hebei, China \\ Correspondence should be addressed to Chang Liu; changtongwuzu1985@163.com
}

Received 27 April 2020; Revised 21 December 2020; Accepted 18 June 2021; Published 28 June 2021

Academic Editor: Jian Ji

Copyright $(2021$ Yan Lv et al. This is an open access article distributed under the Creative Commons Attribution License, which permits unrestricted use, distribution, and reproduction in any medium, provided the original work is properly cited.

In recent years, highways have been built rapidly in China's turfy swamp areas to accommodate economic development. Turfy soil is a type of special soil with high humus and incompletely decomposed plant contents, so its properties are complex and unique. Both the axial and confining pressures of turfy soil increase during embankment filling. Therefore, in this study, three soil tests for analysing the decomposition degree, organic matter content, and triaxial compression under confining and axial pressure increases stress paths were performed to achieve insights into the stress-strain properties of turfy soil. The volumetric and deviatoric strains of turfy soil were summarised to reveal the inner mechanisms of turfy soil, culminating in the establishment of a constitutive model for turfy soil. The results of the constitutive model were compared with the experimental test results to verify the accuracy of the constitutive model. The results showed that the stress-strain and strength of turfy soil are closely related to the organic matter content and decomposition degree. The calculated stress and strain results are also consistent with the experimental results, indicating that this constitutive model can be used to better indicate the original deformation state and strength characteristics of the turfy soil.

\section{Introduction}

Turfy soil is a special type of humic acid-rich humus soil [1] that possesses a unique set of soil properties, such as high organic matter, high compressibility, high moisture, high permeability, a high void ratio, and a low degree of decomposition [2] because of the unique external environment. It also possesses the general characteristics of soft soil, such as nonlinearity, expansion, contraction, plasticity, anisotropy, and rheology [3-5]. The expansion of large-scale construction projects in these turfy soil distribution areas reflects economic development trend, introducing several geotechnical engineering design concerns $[6,7]$. The recent engineering design methods in turfy soil regions have been primarily adopting the general soil constitutive model, which makes it difficult to match to the actual engineering conditions, with large deviations often derived between the theoretical calculation and actual situation. More accurate solutions to this type of problem require a turfy soil constitutive model that considers the stress pathways that can provide a theoretical basis for addressing engineering problems and geotechnical engineering designs in turfy soil regions. Constructions of highways were developed rapidly in turfy swamp area during near decades. In the process of roadbed filling, the overlying load of the soil body increases, and the soil is compressed to produce lateral deformation, resulting in a confining pressure increase in the soil. Under this condition, both confining pressure and axial pressure of the soil body increase. Therefore, the stress-strain properties under CIAI stress path need to be studied in order to obtain the constitutive model of the turfy soil, which can be used to guide the highway constructions in turfy swamp area. In this 
study, we present the constitutive model of turfy soil under confining pressure increases and axial pressure increases (CIAI) stress pathways based on the abovementioned reasons and published case studies.

The equilibrium, deformation, and physical conditions should be considered in numerical soil computations, of which only the physical condition (constitutive relation) depends on the nature of the intrinsic material, which is essential to the numerical calculation [8]. Continuous developments in computer technology and the increasing maturity of the numerical calculation methods have helped solve these numerical equations easily. Therefore, the key to solving the turfy soil problem is to establish the constitutive model that can reasonably describe its soil strength and deformation characteristics [9]. Experimental studies have shown that the stress history, stress pathways, and physical state of the soil, such as its composition structure, have a significant impact on its constitutive model [10-12]. Turfy soil contains a considerable degree of plant residue and organic matter, and the influence of the stress pathways on the constitutive model will be more significant because of the complexity of its composition and structure [13]. Current engineering designs in turfy soil regions primarily adopt the general soil constitutive model, which makes it difficult to match the actual engineering conditions and yields a large deviation between the theoretical and actual situations. Therefore, there is an immediate need to solve this turfy soil constitutive model after considering the stress pathways, which can provide a theoretical basis for addressing engineering problems and geotechnical engineering designs in turfy soil regions.

The influence of the organic matter content in turfy soil on engineering geological characteristics was studied by Nie et al. [14], and the decomposition of turfy soil was studied by Haraguchi et al. and Pitkänen et al. $[15,16]$. They analysed the relationship between the decomposition degree, oxygen consumption rate, biological accumulation, and the regional environment. The mineral distribution at different depths was tested by Nie et al. [17]. A joint analysis of X-ray diffraction and scanning electron microscopic images was performed to explain the mineral distribution and formation mechanism $[18,19]$. All these studies were able to illustrate that the decomposition degree and organic matter of turfy soil have a significant influence on the physical and mechanical properties of turfy soil, leading to the consideration of decomposition degree and organic matter in the constructed constitutive model.

There are many types of soil constitutive models including the elastic model, $E$ - $\nu$ elastic model [20], and a large number of elastic-plastic constitutive models. Based on bounding surface plasticity, a constitutive equation to simulate the nonlinear behaviours of sands under various loadings was proposed by Bardetq, and this model can be used to study sand liquefaction [21]. Gajo and Bigoni proposed a model for stress and plastic strain induced nonlinear, hyperelastic anisotropy in soils; the model is shown to yield very accurate simulations of the evolution of elastic properties from initial directional stiffening to final isotropic degradation [22]. Li et al. proposed a fractional derivative constitutive model of deep artificial frozen soil which was established based on the Nishihara model. This fractional derivative constitutive model was verified to describe the nondecaying creep deformation characteristics of deep artificial frozen soil under high confining pressures [23]. Yao et al. proposed a three-dimensional model for clays adopting a unified hardening parameter independent of stress paths, and it can be used to well simulate stress-strain relationships, shear dilatancy, strain-hardening and softening, and stress path dependence behaviour of overconsolidated clays [24]. Dafalias and Manzari construct a constitutive model for sands with simplicity and intelligibility which can be used to simulate both hardening and softening characteristics [25]. Xiao and Liu proposed an elastoplastic model incorporating state dependence and particle breakage by large-scale triaxial tests, which can be used to predict the stress-strain and particle-breakage behaviours of rockfill materials at various confining pressures [26]. A breakage critical state plane-based bounding surface plasticity model for rockfill materials was proposed by Xiao et al., and it excels in its ability to capture breakage phenomena [27]. The Domaschuk-Valliappan (K-G) model was devised to address the inaccuracies in Poisson's ratio with obvious shear dilatancy [28], followed by different models for different soils $[29,30]$. The modified Duncan-Chang model was proposed specifically for turfy soils in a consolidated drained triaxial test [31], but the model has been only suitable for constant confining pressure. Therefore, the constitutive model under CIAI stress pathways, which considers the decomposition degree and organic matter content, is established to investigate the stress pathways of roadbed filling in turfy soil regions.

The study area is located in Jilin province, Northeast China, which possesses a broad distribution of turfy soil. The area is located to the south of Dunmi Fracture Zone, where there has been a continuous drawdown since the Holocene, with long-term flooding being a primary cause of the observed turfy soil $[32,33]$. The low-lying plain is surrounded by low mountains, especially in the Jiangyuan and Jingyu areas, providing ideal terrain conditions for turfy soil formation [34]. The study was conducted in an area of seasonal frost, with a maximum frozen depth of around $180 \mathrm{~cm}[35,36]$. Recent drill-hole results had revealed the distribution of a thick clay layer under the turfy soil layer, which prevented water infiltration into the turfy soil [33]. Two groups of soil samples were obtained in the Jiangyuan and Jingyu areas, and the exact sample locations are shown in Figure 1, and every soil sample was prepared for the organic matter content, decomposition degree, and triaxial tests.

\section{Tests}

2.1. Decomposition Degree Test. Each turfy soil sample was selected and divided into four equal parts using the fixed centre method, with two of the soil samples sealed in vacuum bags for the organic matter content test and the other two soil samples saved for the plant residue separation test. The 

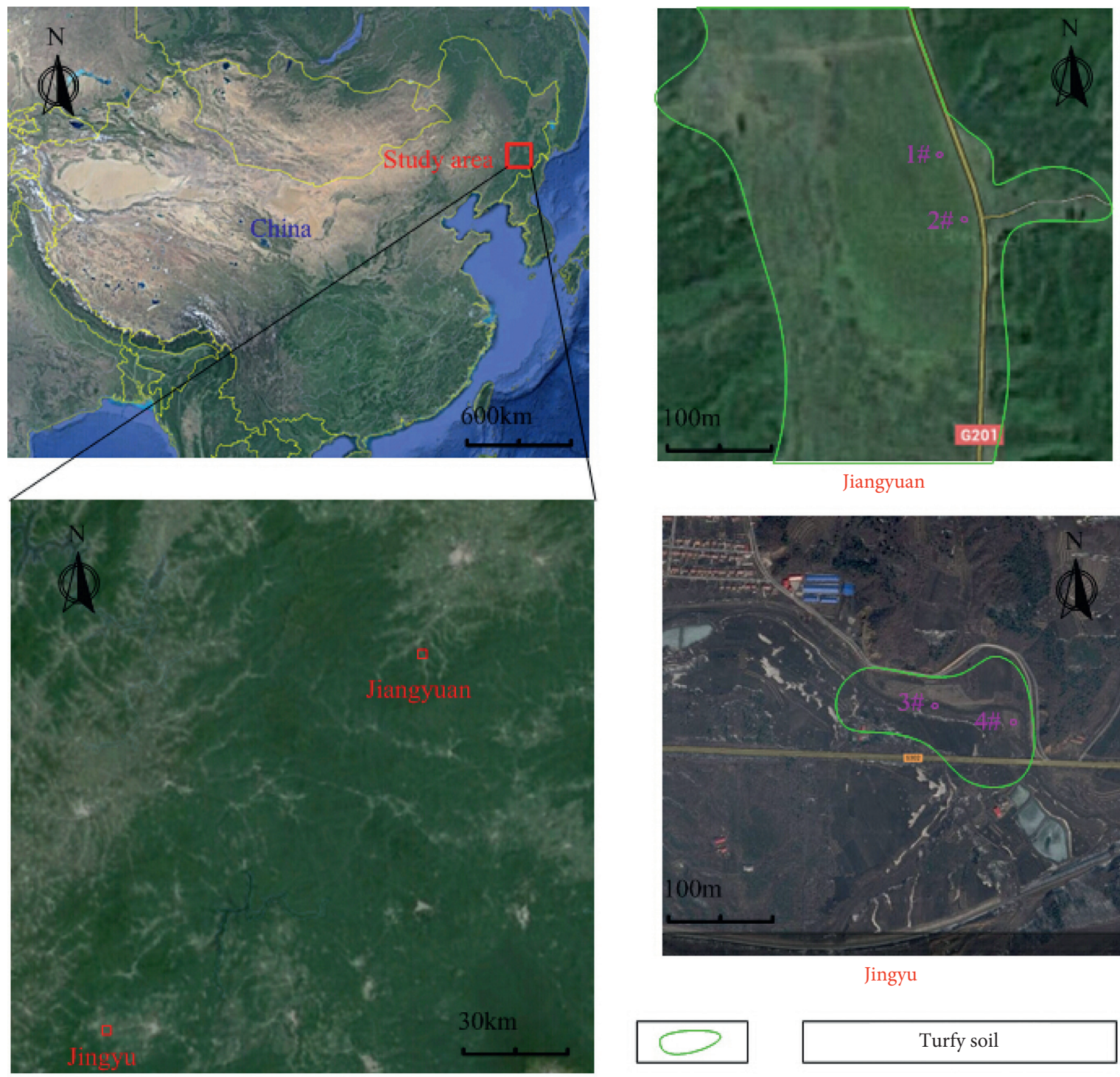

Jiangyuan

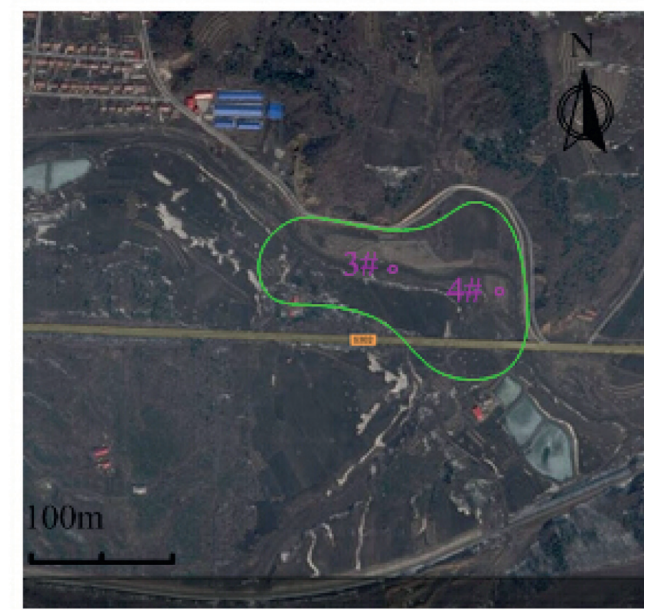

Jingyu

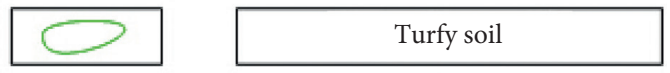

FIgUre 1: Aerial views of the study area and sampling location.

soil samples were then cut into $1.5 \mathrm{~cm}^{3}$ pieces with a sharp knife for the plant residue separation test and placed into a beaker, followed by the addition of $\mathrm{NaOH}$ solution $(\sim 3 \%$ concentration). The mixture was then boiled for at least $2 \mathrm{~h}$ to completely separate the plant residue and cementing material, followed by sieving the soil through a $0.25 \mathrm{~mm}$ mesh, rinsing the sieved material, and removing the lime, humus, and minerals. The resultant plant residue was then placed into a round-bottom bowl and dried in an oven at $65^{\circ} \mathrm{C}$. The dried plant residue was then removed and separated into two samples, one of which was sealed in a dry vacuum bag for the organic matter content test and another sample was tested via the kerosene and volume method to determine the volume of undecomposed plant residue, as shown in Figure 2.

The degree of turfy soil decomposition can be calculated using the following formula:

$$
\begin{aligned}
F & =\left(1-\frac{V_{c}^{\prime}(1+e)}{V_{c}}\right) \times 100, \\
V_{c} & =V_{c s}(1+e)
\end{aligned}
$$

where $F$ is the decomposition of turfy soil (\%), $V_{c s}$ is the volume of plant residues, organic matter, and mineral particles in the carboniferous soil, $V_{c}^{\prime}$ is the volume of undecomposed plant residue after baking $\left(\mathrm{cm}^{3}\right), e$ is the void ratio of the turfy soil, and $V_{c}$ is the volume of the turfy soil before the test $\left(\mathrm{cm}^{3}\right)$. The decomposition results are shown in Table 1.

2.2. Organic Matter Content Test. The ignition loss method is used to test the organic matter content of the soil samples because the turfy soil is rich in organic matter. 


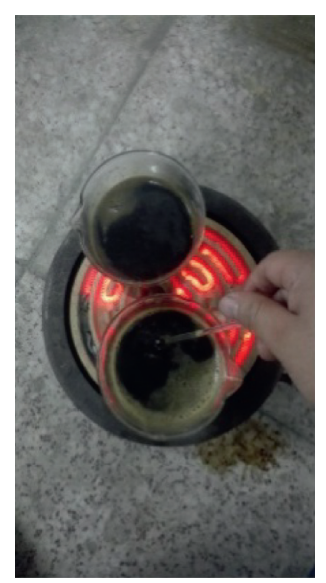

(a)

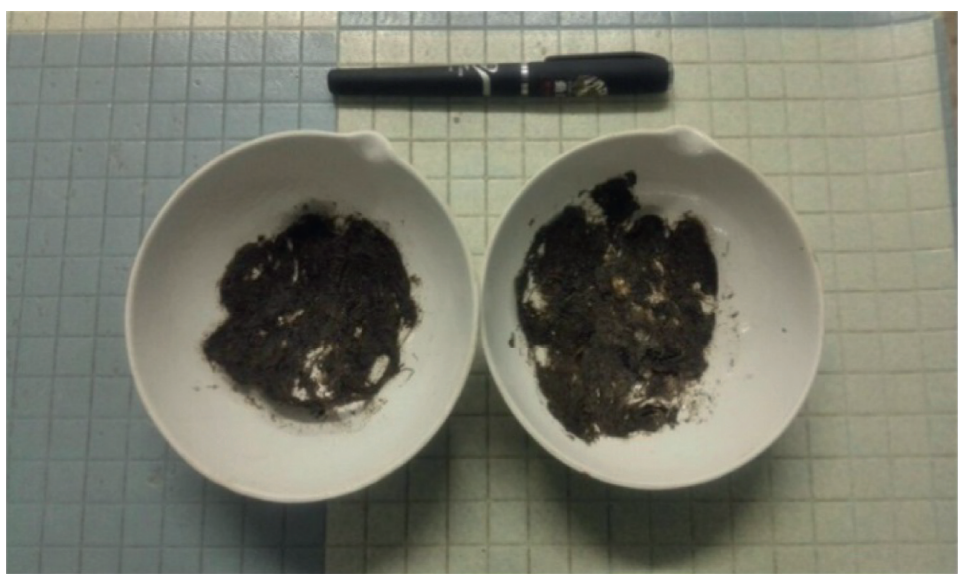

(b)

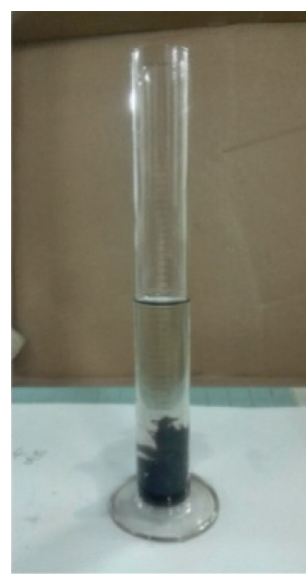

(c)

Figure 2: Test of decomposition degree.

TABle 1: The test result of decomposition degree of turfy soil.

\begin{tabular}{lcccc}
\hline Soil samples & $\# 1$ & $\# 2$ & $\# 3$ & $\# 4$ \\
\hline$e$ & 7.32 & 5.82 & 4.31 & 1.79 \\
$V_{c s}\left(\mathrm{~cm}^{3}\right)$ & 1.80 & 2.20 & 2.82 & 5.38 \\
$V_{c}^{\prime}\left(\mathrm{cm}^{3}\right)$ & 1.10 & 1.02 & 0.90 & 0.40 \\
$F(\%)$ & 38.99 & 53.62 & 68.14 & 88.10 \\
\hline
\end{tabular}

The soil samples were first oven-dried at $65^{\circ} \mathrm{C}$ for $24 \mathrm{~h}$ continuously, ground into a powder, and sieved through a $0.5 \mathrm{~mm}$ mesh. The mass of the sieved powder $m_{1}(\sim 1 \mathrm{~g})$ was placed in a high-temperature furnace at $550^{\circ} \mathrm{C}$ for $1 \mathrm{~h}$, the soil sample was measured to determine its weight loss, and the process was repeated (burning and weighing) until the weight loss between the two adjacent steps was $<0.5 \mathrm{mg}$, which yielded the final weight $m_{2}$ (g). The sequestration plant residue test was designed according to the test process for ignition loss measurements, with the weight of the plant residue following ignition denoted as $m_{c}^{\prime}(\mathrm{g})$.

From the definition of ignition loss, the loss of turfy soil, that is, organic matter content, could be calculated from the following formula, as seen in equation (2).

$$
S=\frac{\left(G_{1}-G_{2}\right)}{G_{1} \times 10},
$$

where $G^{1}$ is the mass of turfy soil before burning and $G_{2}$ is that after burning. The ignition loss of the turfy soil (without plant residue) $S_{h}$ was calculated using the following formula:

$$
S_{h}=\frac{\left(m_{1}-m_{2}-M_{3}\right)}{m_{1}-M_{4}} \times 100 \%,
$$

where $M_{3}$ is the burning loss of the plant residue existing in the $m_{1}$ turfy soil and $M_{4}$ is the weight of the plant residue existing in the $m_{1}$ turfy soil. $M_{3}$ and $M_{4}$ can be calculated as follows:

$$
\begin{aligned}
& M_{3}=\frac{m_{1} m_{c}^{\prime}(1-F)}{V_{c}^{\prime} \rho_{s}}, \\
& M_{4}=\frac{m_{1} \rho_{c}^{\prime}(1-F)}{\rho_{s}},
\end{aligned}
$$

where $V_{c}^{\prime}$ is the volume of the plant residue used in the decomposition degree test, $m_{c}^{\prime}$ is the weight of the corresponding plant residue following ignition at $550^{\circ} \mathrm{C}, \rho_{c}^{\prime}$ is the density of plant residue after drying, and $\rho_{s}$ is the soil particle density of the turfy soil. The ignition loss results are shown in Table 2.

\subsection{The Physical and Mechanical Index Measurements.} The summary of the measurement results of basic physical and mechanical properties of turfy soil is presented in Table 3 . The results suggest that the organic matter content and decomposition degree in turfy soil possess a certain correlation with their physical and mechanical indices.

Both the organic matter content and moisture content exhibited obvious decreases with increasing natural soil particle density, whereas the opposite trend was observed with the decomposition degree. The coefficient of compressibility, compression index, and swelling index of turfy soil were also positive with organic matter content and moisture content, whereas they were negative with the decomposition degree. The organic matter content and decomposition degree of turfy soil, therefore, exhibited a great influence on the physical and mechanical indices of turfy soil. The stress-strain, strength, and damage characteristics were also closely related to the decomposition degree and organic matter content of turfy soil.

2.4. Triaxial Test. The consolidation and drainage compression tests of turfy soil with CIAI stress paths were carried out. Unloading and loading tests were conducted on the same turfy soil specimen under CIAI stress pathways. CIAI 
TABLE 2: The results of ignition loss.

\begin{tabular}{|c|c|c|c|c|c|c|}
\hline Soil samples & $S(\%)$ & $m_{1}(\mathrm{~g})$ & $m_{2}(\mathrm{~g})$ & $m_{c}^{\prime}(\mathrm{g})$ & $\rho_{c}^{\prime}\left(\mathrm{g} / \mathrm{cm}^{3}\right)$ & $S_{h}(\%)$ \\
\hline $1 \#$ & 74.23 & 1.16 & 0.30 & 0.50 & 0.71 & 77.48 \\
\hline $2 \#$ & 64.55 & 1.04 & 0.37 & 0.32 & 0.70 & 69.19 \\
\hline $3 \#$ & 62.03 & 0.83 & 0.31 & 0.31 & 0.70 & 63.97 \\
\hline 4\# & 38.96 & 1.06 & 0.65 & 0.19 & 0.65 & 38.63 \\
\hline
\end{tabular}

$S$ is the total ignition loss of turfy soil (organic matter content of turfy soil); $m_{1}$ is the weight of turfy soil before test; $m_{2}$ is the weight of turfy soil after test; $m_{c}^{\prime}$ is the ignition loss of plant residues; $\rho_{c}^{\prime}$ is the dry density of plant residues; $S_{h}$ is the ignition loss of humus parts.

TABle 3: Decomposition, organic matter, and basic physical and mechanical properties of turfy soil.

\begin{tabular}{|c|c|c|c|c|c|c|c|c|}
\hline $\begin{array}{l}\text { Soil } \\
\text { sample }\end{array}$ & $\begin{array}{c}\text { Decomposition } \\
\text { degree, } F(\%)\end{array}$ & $\begin{array}{c}\text { Organic } \\
\text { matter } \\
\text { content, } \\
S_{h}(\%)\end{array}$ & $\begin{array}{c}\text { Natural } \\
\text { density, } \\
\rho\left(\mathrm{g} / \mathrm{cm}^{3}\right)\end{array}$ & $\begin{array}{c}\text { Soil particle } \\
\text { density, } \\
\rho_{s}\left(\mathrm{~g} / \mathrm{cm}^{3}\right)\end{array}$ & $\begin{array}{c}\text { Moisture } \\
\text { content, } \\
\omega(\%)\end{array}$ & $\begin{array}{c}\text { Coefficient of } \\
\text { compressibility, } \\
a_{1-2}\left(\mathrm{MPa}^{-1}\right)\end{array}$ & $\begin{array}{l}\text { Compression } \\
\text { index, } C_{c}\end{array}$ & $\begin{array}{l}\text { Swelling } \\
\text { index, } C_{s}\end{array}$ \\
\hline$\# 1$ & 38.99 & 77.48 & 0.93 & 1.83 & 321.8 & 7.24 & 2.4233 & 0.4802 \\
\hline$\# 2$ & 53.62 & 69.19 & 1.06 & 1.91 & 279.6 & 5.93 & 2.5835 & 0.4641 \\
\hline$\# 3$ & 68.14 & 63.97 & 1.12 & 1.92 & 209.7 & 5.81 & 1.5933 & 0.2927 \\
\hline$\# 4$ & 88.10 & 38.63 & 1.45 & 2.21 & 82.6 & 0.74 & 0.3135 & 0.0178 \\
\hline
\end{tabular}

is confining pressure increases and axial pressure increases. Under the condition of uniform consolidation, the confining pressure and axial pressure increased, and the proportion of the increase was constant $\left(\Delta \sigma_{3} / \Delta \sigma_{1}=0.4\right)$ under the condition of different consolidation stress $(=50 \mathrm{kPa}, 100 \mathrm{kPa}$, $200 \mathrm{kPa}$, and $300 \mathrm{kPa}$ ). The stress path diagram is shown in Figure 3. The $p-\varepsilon_{v I}$ relationship curve was determined for the turfy soil samples (\#1\#4), as shown in Figure 4.

Volume expansion occurred in soil samples \#2 and \#3 during unloading at low initial consolidation stresses $\left(\sigma_{3 c} \leq 50 \mathrm{kPa}\right)$, especially sample \#3 at a stress of $50 \mathrm{kPa}$, where a volume expansion of $0.39 \%$ was observed because of the high organic content. The microstructure of the turfy soil in Figure 5 indicates that the organic matter particles in sample \#3 are significantly small, possessing primarily circular granular particles, such that the connection between particles is not tight and micropores develop, leading to the formation of a flocculation structure bonded together in a chain distribution. The chain structure of the micropores formed by the organic matter particles during the loading process will be populated with close-grained particles when the consolidation stress level is low, and the cementation of the tension effect will become more obvious, with this type of chain structure gradually returning to its original shape when under tension during unloading.

Soil sample \#1 underwent a larger volume contraction compared to other samples when the consolidation stress level was increased, primarily because the decomposition degree of sample \#1 was the smallest of the four turfy soil groups. This suggests that the hydraulic pathway formed by the plant fibre and plant residual root is greater in sample \#1, meaning that when the consolidation stress level is higher, this pathway is damaged, and the drainage process is limited by a certain degree. Therefore, a drainage lag phenomenon occurs at the start of unloading.

The $\varepsilon_{v I}-p$ relationship curve for turfy soil samples under the CIAI pathways is drawn on a semilog plot to reflect the development rule of the volumetric strain along with the average stress more clearly, as shown in Figure 6. The initial consolidation stress has an important effect on the $\varepsilon_{v}-\ln p$ curve, with the increase in the initial consolidation stress of the same undisturbed turfy soil increasing the segmentation point of $\varepsilon_{v}-\ln p$. This indicates that the increase in the initial consolidation stress also increases the yield stress, likely caused by compressive hardening.

The four curves for each group of turfy soil exhibit no obvious changes under the same consolidation stress, but the slope of the straight line exhibits the following general trend: $\# 3>\# 2>\# 4>\# 1$. This is because the organic matter content (does not contain residual roots and plant fibre) in turfy soil \#3 is less than that in samples \#2 and \#1, and the decomposition degree in turfy soil \#3 is more than those in samples $\# 2$ and \#1, possessing small organic matter particles that form weaker embedding and interlocking bonds, such that turfy soil \#3 undergoes greater volume deformation at the same loading mode.

\subsection{Partial Strain Properties of Turfy Soil When Loading and} Unloading. We can determine the turfy soil deviatoric strain based on the measured data and the formulation under the CIAI stress pathways. The deviatoric stress and deviatoric strain relations of turfy soils \#1 \#4 are shown in Figure 7.

The four sample groups exhibited only a low level of recoverable elastic strain after unloading, with most of the deformation being unrecoverable plastic strain. This suggests that a larger displacement exists between the organic matter molecules and the skeleton structure consists of internal plant residue and plant fibre as the axial and radial stresses increase. The concept of the elastic deviator strain ratio is introduced to better highlight the differences between the corresponding elastic and plastic strains of the four turfy soil samples under different consolidation states, which is expressed as 


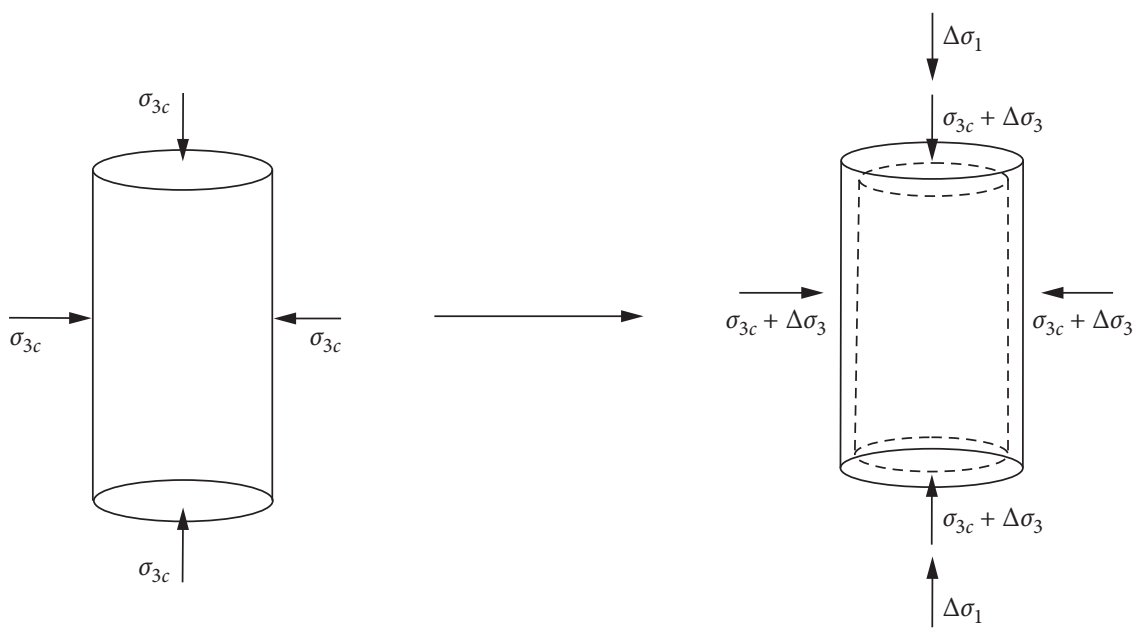

FIGURE 3: The stress path diagram.

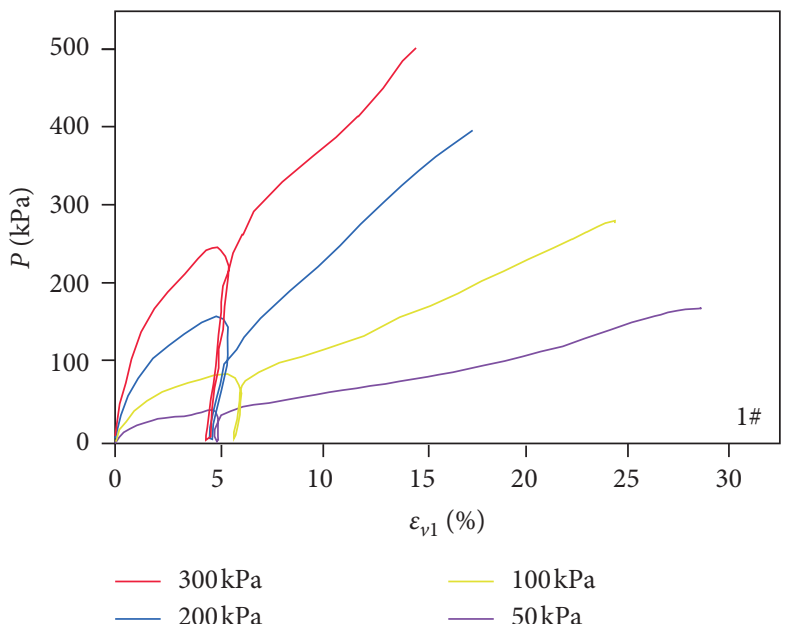

(a)

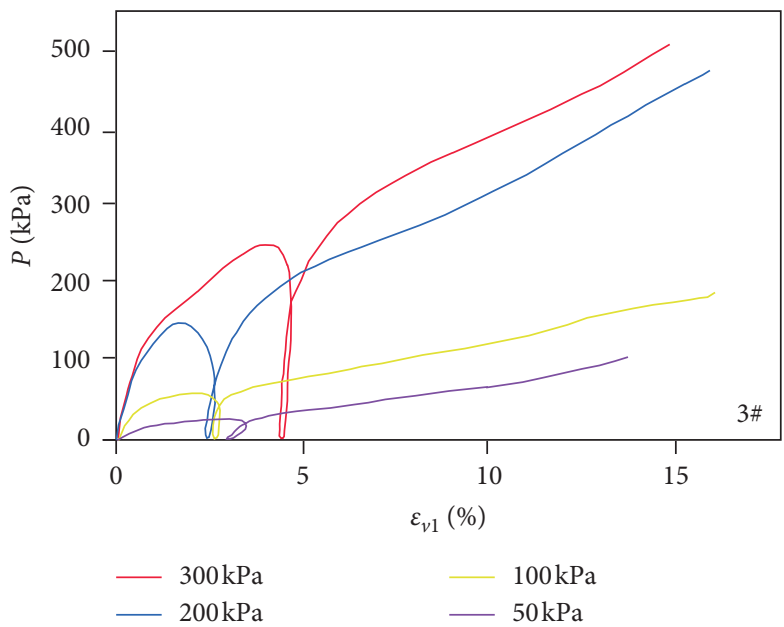

(c)

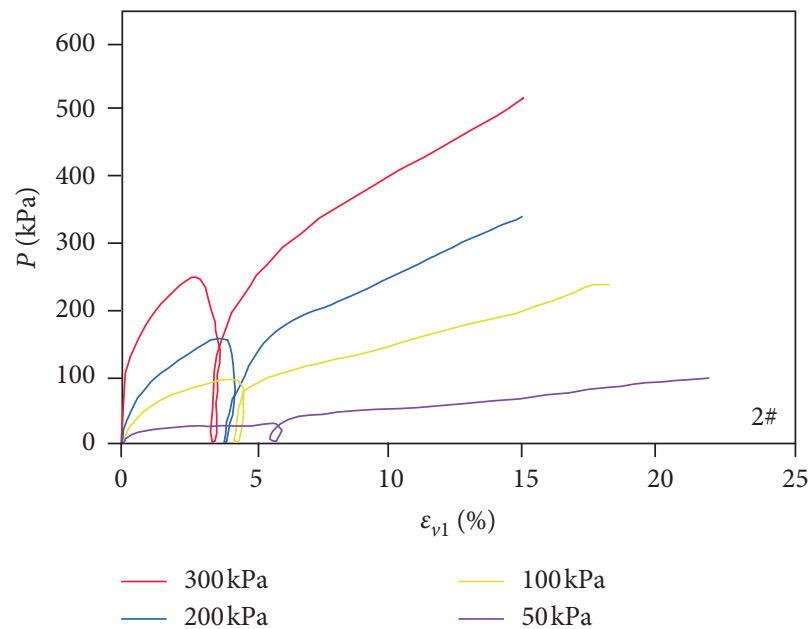

(b)

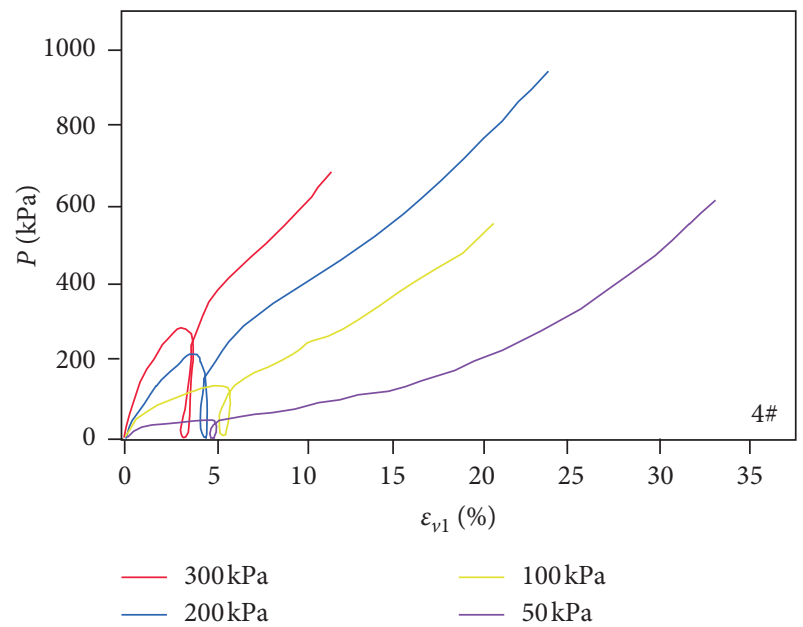

(d)

FIGURE 4: $p-\varepsilon_{v I}$ relationship curve for \#1 \#4 undisturbed turfy soil samples under unloading and reloading. 


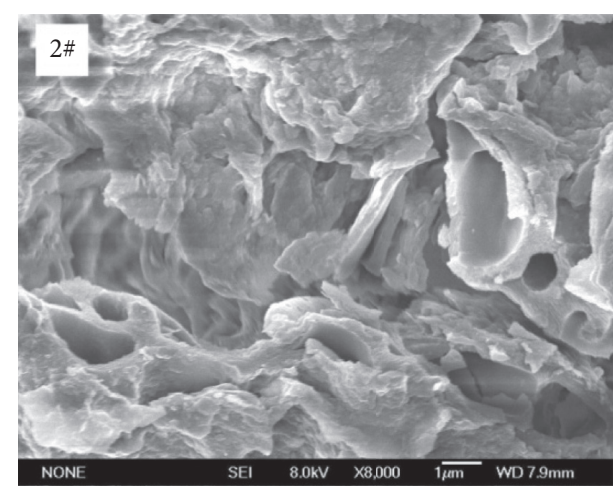

(a)

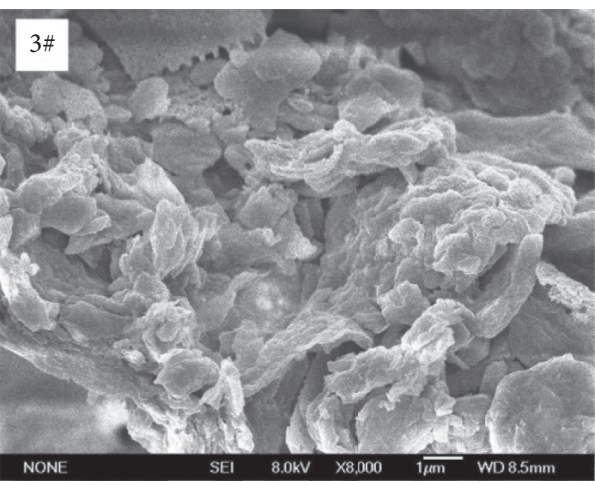

(b)

FIGURE 5: Microstructure of undisturbed turfy soil by scanning electron microscopy (SEM).

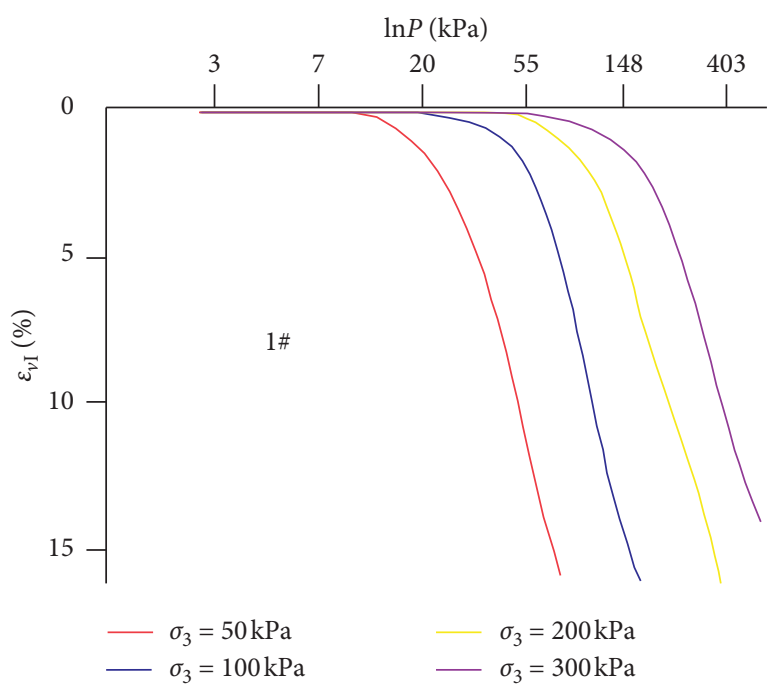

(a)

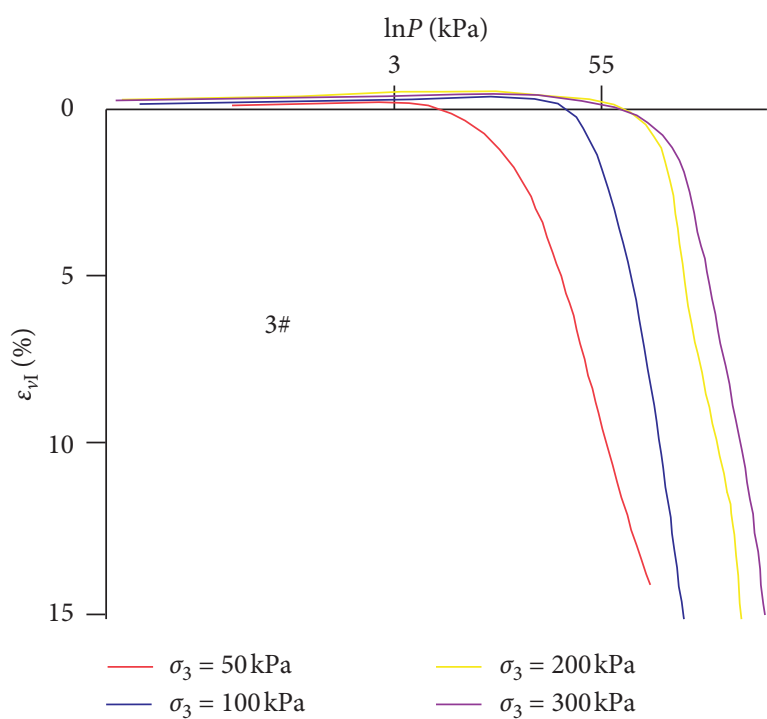

(c)
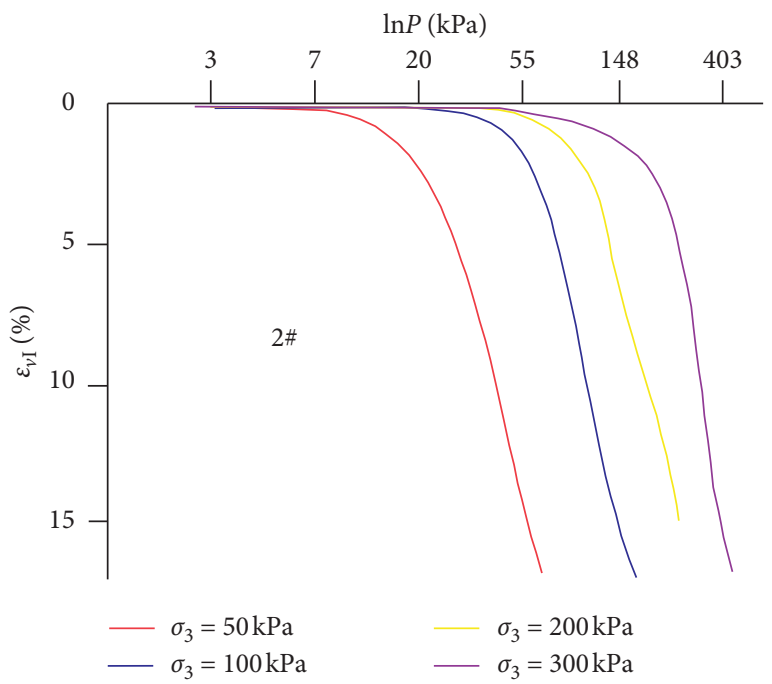

(b)

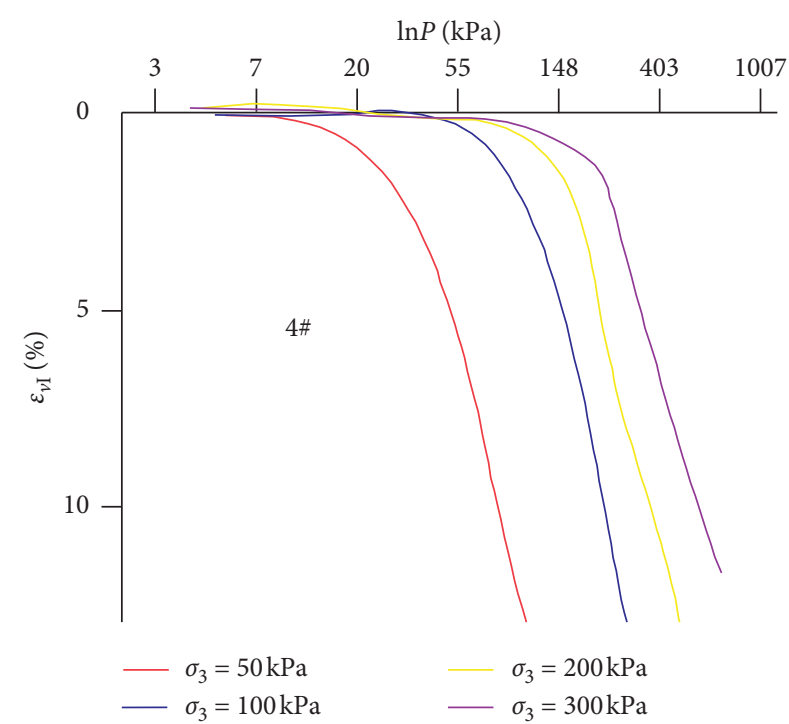

(d)

FIGURE 6: $\varepsilon_{v I}-p$ relationship curve for \#1 \#4 undisturbed turfy soil samples in the semilog coordinate. 


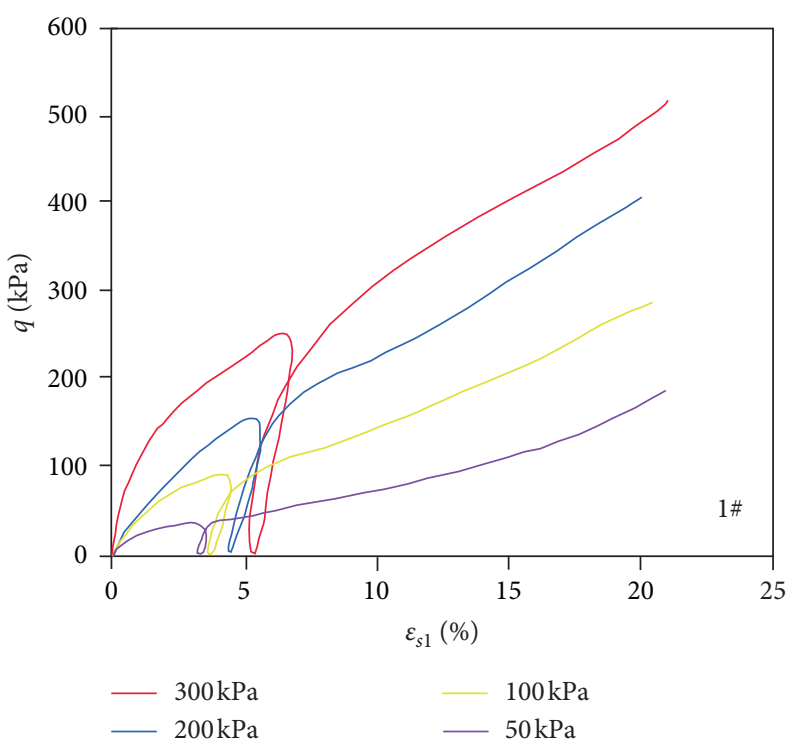

(a)

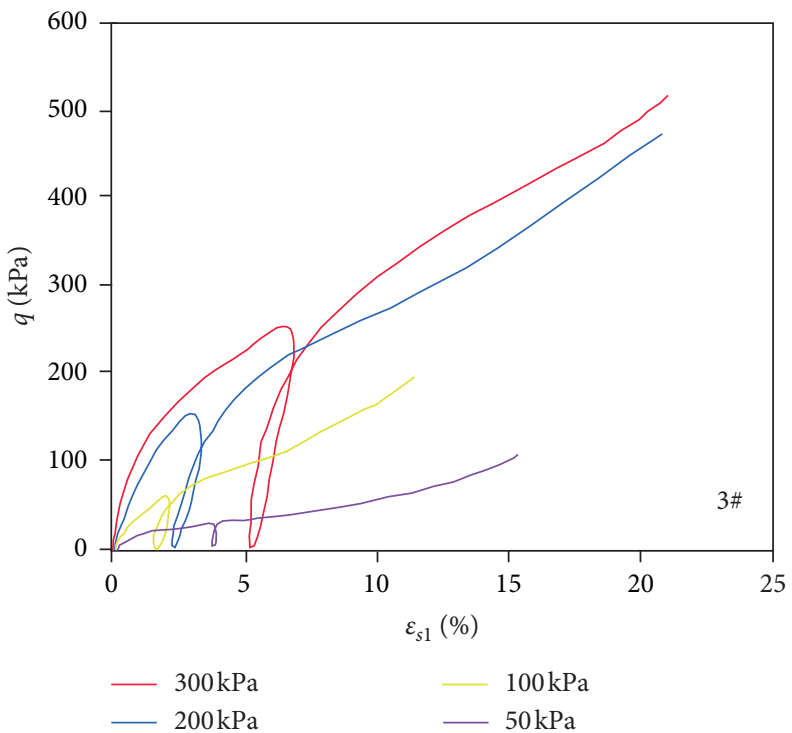

(c)

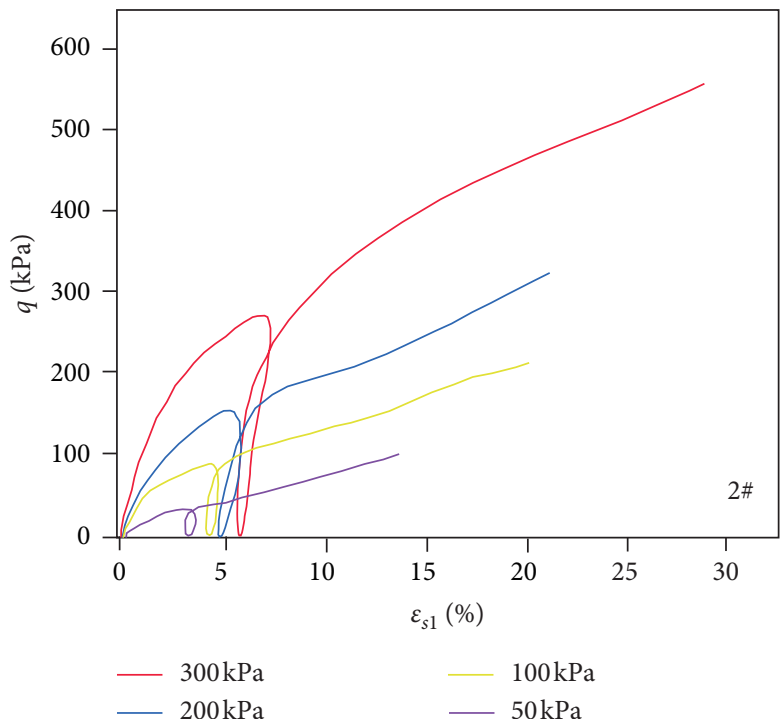

(b)

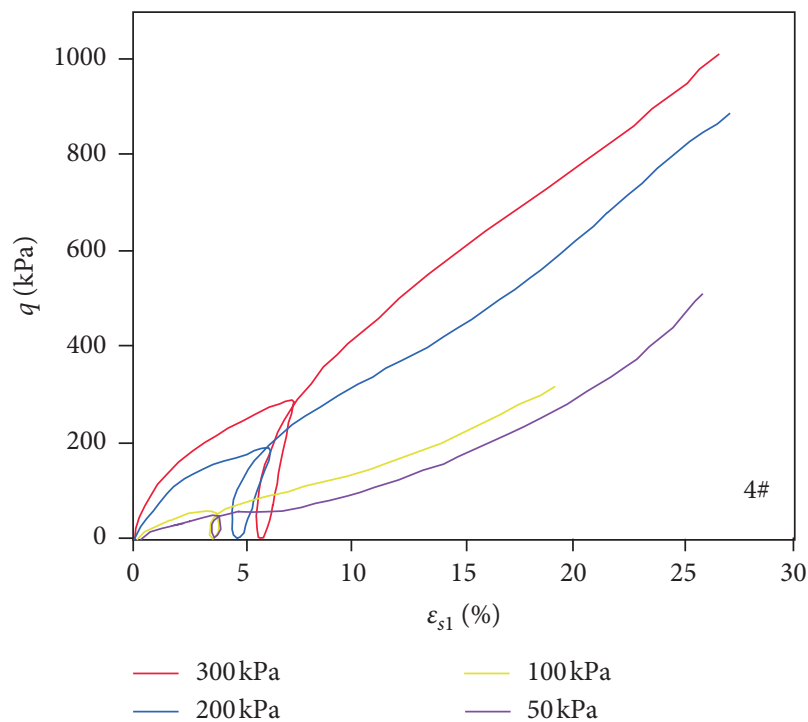

(d)

FIgURE 7: The deviatoric stress and deviatoric strain relations of undisturbed turfy soils \#1 \#4.

$$
\lambda=\frac{p_{a}\left(\varepsilon_{s I}^{0}-\varepsilon_{s I}^{z}\right)}{q_{o}},
$$

where $\lambda$ is the elastic deviatoric strain ratio, $q_{o}$ is the deviatoric stress during unloading, $\varepsilon_{s I}^{0}$ is the deviatoric strain at the initial unloading, $\varepsilon_{s I}^{z}$ is the deviatoric strain when the unloading is complete, and $p_{a}$ is the standard atmospheric pressure. The calculation results are listed in Table 4 .

The elastic strain ratios of turfy soils \#3 and \#1 yield the minimum and maximum ratios, respectively, when the initial consolidation stress is low because turfy soil \#3 contains a large amount of organic matter particles comprising small flocculated structures. There are micropores between the particles when the initial consolidation stress is low, with the increase in the axial and confining pressures
TABLE 4: Elastic deviatoric strain ratio of turfy soil samples \#1 \#4 under different consolidation states (\%).

\begin{tabular}{lccccccccc}
\hline $\begin{array}{l}\text { Consolidation stress } \\
(\mathrm{kPa})\end{array}$ & \multicolumn{2}{c}{$\# 1$} & \multicolumn{2}{c}{$\# 2$} & \multicolumn{2}{c}{$\# 3$} & \multicolumn{2}{c}{$\# 4$} \\
& $q_{o}$ & $\lambda$ & $q_{o}$ & $\lambda$ & $q_{o}$ & $\lambda$ & $q_{o}$ & $\lambda$ \\
\hline 50 & 37 & 0.87 & 36 & 0.56 & 28 & 0.14 & 40 & 0.68 \\
100 & 94 & 0.58 & 89 & 0.45 & 65 & 0.35 & 61 & 0.46 \\
200 & 163 & 0.52 & 153 & 0.65 & 154 & 0.42 & 207 & 0.50 \\
300 & 260 & 0.43 & 270 & 0.44 & 257 & 0.51 & 293 & 0.45 \\
\hline
\end{tabular}

generating a relative displacement between the particles and structure units, which changes the original particle positions and fills the micropores, such that the deformation cannot recover upon unloading, resulting in permanent 
deformation. Turfy soil \#1, which possesses considerable plant residue and plant fibres, exhibited little destruction of the tubular structure of the plant residue and plant fibres when the consolidation stress was low, with the hydrated film thinning because of the squeezing out of the water existing in the tubular structure during loading, resulting in a tensile state due to cementation between the soil particles and plant residue. The decrease in the axial and radial stresses during unloading as the water re-enters the tubular structure of the plant residue and plant fibres leads to the recovery of the hydrated film, as well as some of the deformation caused by the plant residue and plant fibres, and this may be the reason for turfy soil \#1 yielding the largest elastic strain ratio.

The elastic strain ratio of turfy soil sample \#3 was larger than those of the other samples when the initial consolidation stress was higher $\left(\sigma_{3 c} \geq 200 \mathrm{kPa}\right)$ because it is easier for soil consolidation due to the presence of high organic matter content. The micropores in the turfy soil were filled by organic matter particles after the sample was held in a state of compression consolidation for a period of time. However, when the axial and confining pressures increased, it became difficult to produce the relative displacement between particles, with the micropores compressed with organic matter particles, soil particles, and a hydration shell. Water then reentered the pore space between the soil particles during unloading, resulting in the larger elastic strain ratio.

\subsection{Deviatoric Strain of the Turfy Soil without Unloading.} The $\varepsilon_{s I}-\ln q$ curves of the turfy soil samples under different consolidation states are shown in Figure 8. The semilog plots of the $\varepsilon_{s I}-q$ curves of the four soil samples exhibit similar shapes, meaning that the curves follow a power function when the deviatoric strain is low and then become linear at the yield strain, with different intercepts and slopes for different soil samples.

The shear elastic moduli of the four turfy soils are highly similar. This is because while the soil samples with the skeleton structure and micropores were further compressed and filled during loading under the CIAI pathways, with little porosity left in the samples after loading, the deviatoric strain was primarily dependent on the axial variable, and the axial strains of the four soil samples were similar during shearing.

\section{Model Construction}

3.1. Volumetric Strain of Turfy Soil. The $\varepsilon_{v}-p$ curve of turfy soil can be broken into a power function curve and a straight line, as shown in Figure 9, such that the $\varepsilon_{v}-p$ curve can be expressed as the following set of functions:

$$
\varepsilon_{v I}= \begin{cases}H_{1}\left(\frac{p}{p_{a}}\right)^{B_{1}}, & p \leq p_{y}, \\ H_{2}+B_{2} \ln \left(\frac{p}{p_{a}}\right), & p>p_{y},\end{cases}
$$

where $H_{1}$ and $H_{2}$ and $B_{1}$ and $B_{2}$ are experimental parameters, $H_{1}$ and $B_{2}$ correspond to the intercept and slope of the $\varepsilon_{v I}-\ln p$ curve, $H_{2}$ equals $\varepsilon_{v I}$ when $p \longrightarrow p_{a}$, and $p_{y}$ is the yield stress.

The yield spherical stress $p_{y}$ is dependent on the decomposition degree $F$, organic content $S_{h}$, and the initial consolidation stress $\sigma_{3 c}$. A total of 16 samples were selected for the multivariate linear regression, with the regression model constructed as follows:

$$
y=\beta_{0}+\beta_{1} x_{1}+\beta_{2} x_{2}+\beta_{3} x_{3}
$$

where $x_{1}, x_{2}$, and $x_{3}$ represent $\sigma_{3 c}, F$, and $S_{h}$, respectively. The calculated results are as follows: $\beta_{0}=345.046, \beta_{1}=0.827$, $\beta_{2}=-2.096$, and $\beta_{3}=-3.471$; the confidence intervals for $\beta_{0}, \beta_{1}, \beta_{2}$, and $\beta_{3}$ are $(114.003,576.088),(0.748,0.907)$, $(-3.753,-0.439)$, and $(-5.540,-1.403)$.

The results of the residual analysis in Figure 9 indicate that the residue of the 16 samples is close to zero, meaning that the regression model is in good agreement with the original data. The statistical analysis yields the following results: $R^{2}=0.978, F=132.093$, and $P_{F}=0.00<0.05$, confirming that the regression model is feasible. Therefore, the yield spherical stress of the regression model can be obtained as follows:

$$
p_{y}=345.046+0.827 \sigma_{3 c}-2.096 F-3.471 S_{h} .
$$

The segmentation points of formula (7) were determined using $p_{y}$, allowing the experimental parameters $\left(H_{1}, H_{2}, B_{1}\right.$, and $B_{2}$ ) to be determined through nonlinear fitting. The results are listed in Table 5.

$H_{1}$ decreases with an increase in consolidation stress, as shown in Table 5 , and the relationship between $\ln \left(\sigma_{3 c} / p_{a}\right)$ and $\ln H_{1}$ is shown in Figure 10. $H_{1}$ and $\sigma_{3 c}$ exhibit a linear correlation in log-log space, which can be described as follows:

$$
H_{1}=m_{1}\left(\frac{\sigma_{3 c}}{p_{a}}\right)^{\lambda_{1}},
$$

where $m_{1}$ and $\lambda_{1}$ are model parameters. The calculation results are detailed in Table 6 .

The volumetric strain $\varepsilon_{v I}$ exhibited only minor differences with increasing yield spherical stress for the same turfy soil samples when considering the relationship between the experimental parameter $\mathrm{H}_{2}$ and $\sigma_{3 c}$, where $\mathrm{H}_{2}$ represents the pressure sensitivity of the turfy soil after yielding. $\mathrm{H}_{2}$ and $\sigma_{3 c}$ also exhibit a linear correlation in log-log space, which can be described as follows:

$$
H_{2}=m_{2}+\lambda_{2} \ln \left(\frac{\sigma_{3 c}}{p_{a}}\right),
$$

where $m_{2}$ and $\lambda_{2}$ are model parameters. The calculation results are listed in Table 6.

The volumetric strain of turfy soil under CIAI pathways can be described as follows: 


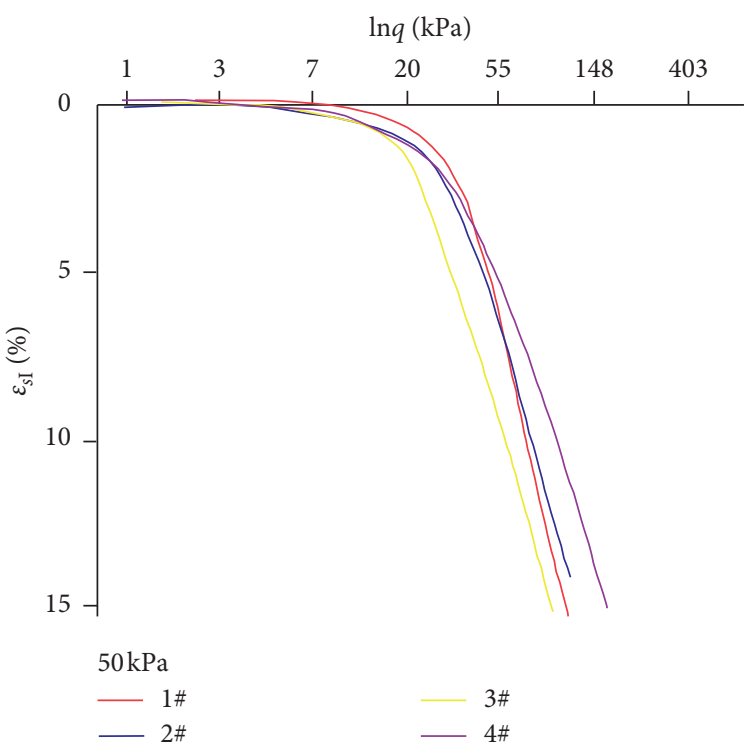

(a)

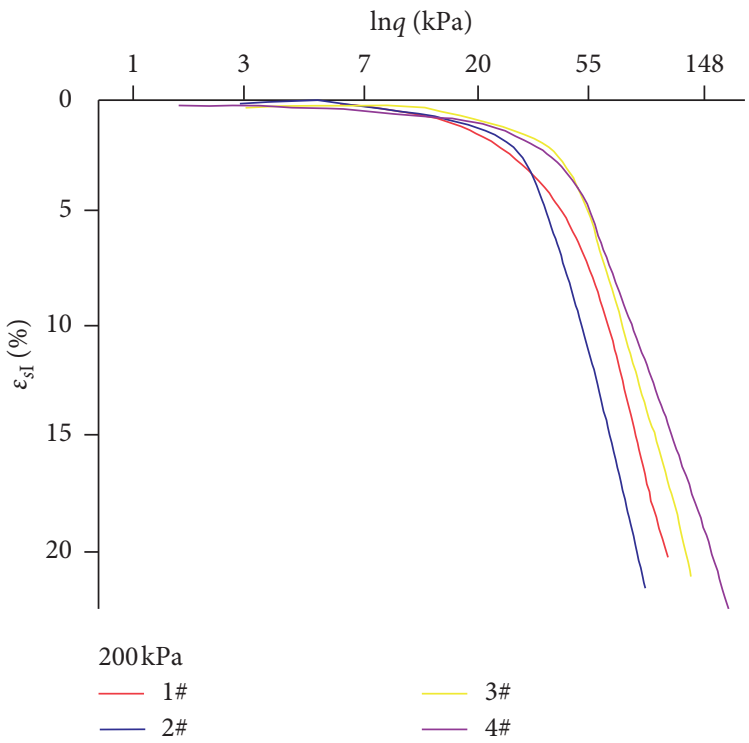

(c)

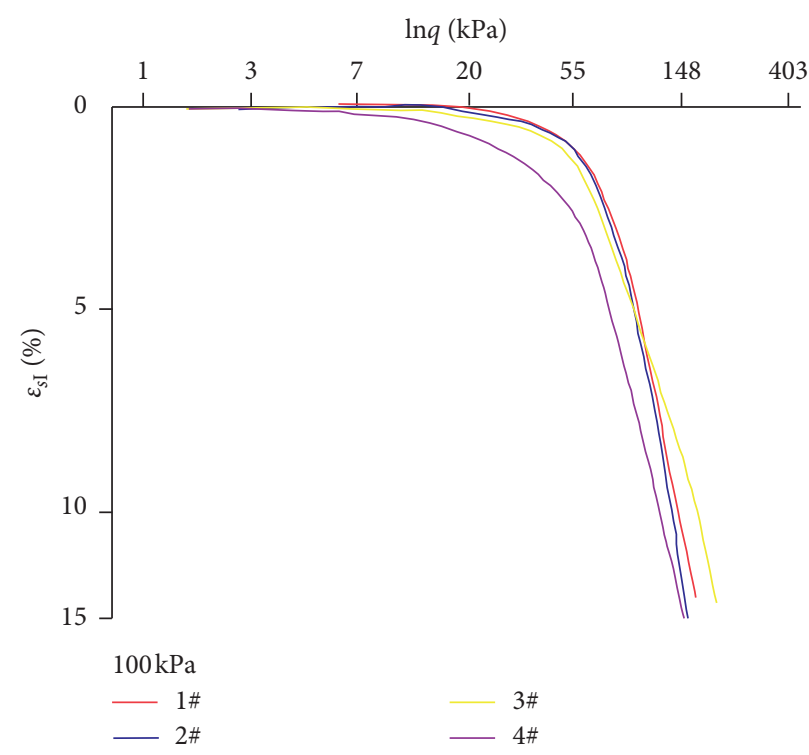

(b)

$\ln q(\mathrm{kPa})$

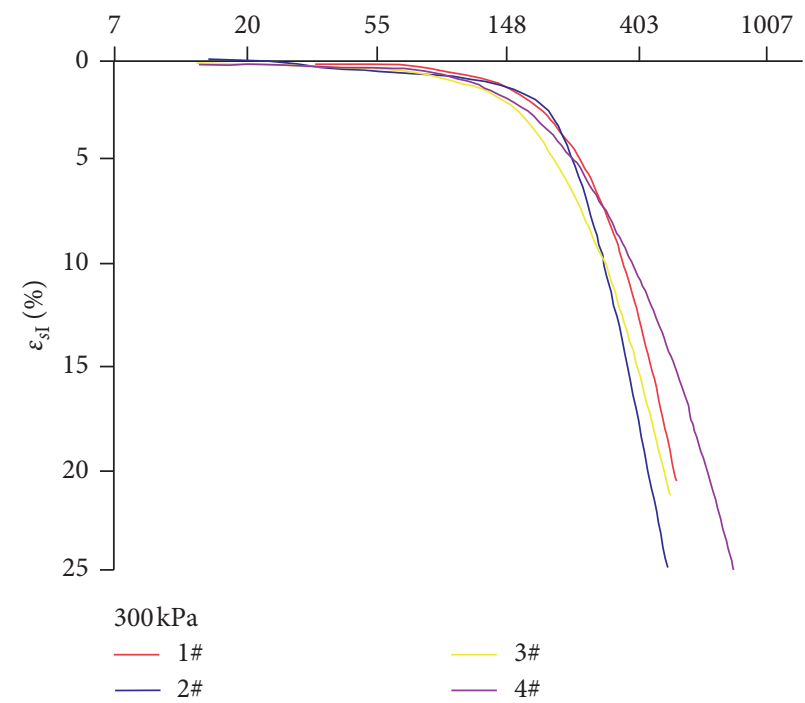

(d)

Figure 8: $\varepsilon_{s I}-\ln q$ curves of turfy soil under CIAI stress paths.

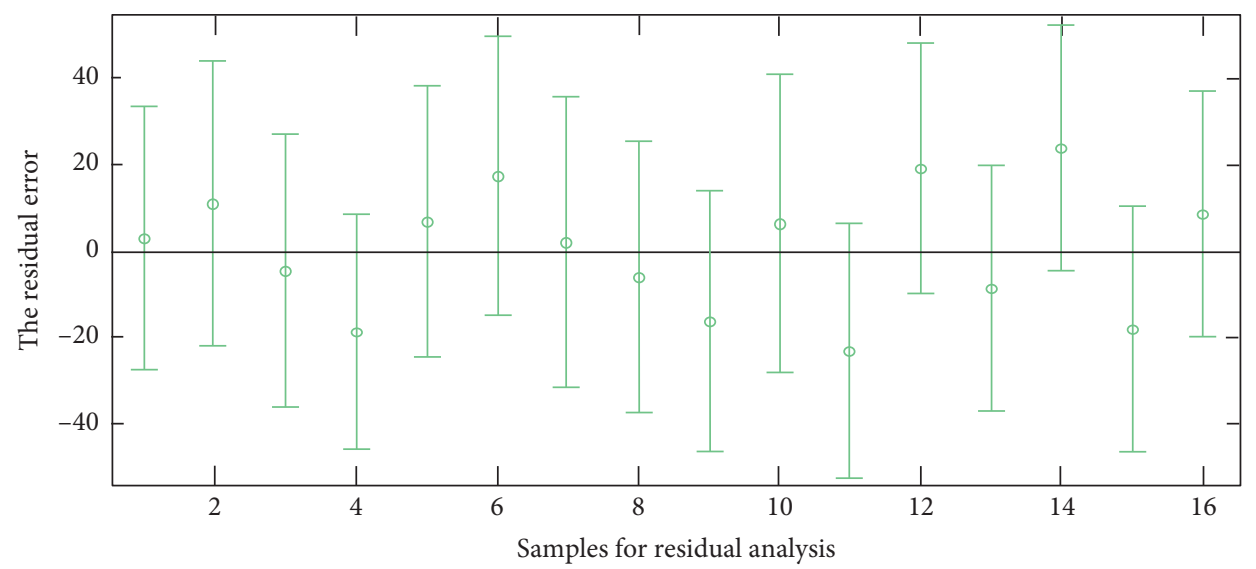

Figure 9: Residual analysis of yield spherical stress regression model of turfy soil. 
TABLe 5: Test result of $H_{1}, H_{2}, B_{1}$, and $B_{2}$.

\begin{tabular}{|c|c|c|c|c|c|c|c|c|}
\hline \multirow{2}{*}{ Consolidation stress $(\mathrm{kPa})$} & \multicolumn{4}{|c|}{$\# 1$} & \multicolumn{4}{|c|}{$\# 2$} \\
\hline & $H_{1}$ & $B_{1}$ & $\mathrm{H}_{2}$ & $B_{2}$ & $H_{1}$ & $B_{1}$ & $\mathrm{H}_{2}$ & $B_{2}$ \\
\hline 50 & 1.275 & 2.986 & 0.201 & 0.153 & 0.719 & 2.266 & 0.214 & 0.157 \\
\hline 100 & 0.074 & 2.191 & 0.081 & 0.150 & 0.065 & 3.403 & 0.049 & 0.146 \\
\hline 200 & 0.017 & 2.544 & -0.013 & 0.134 & 0.012 & 2.689 & -0.019 & 0.136 \\
\hline \multirow[t]{2}{*}{300} & 0.004 & 2.861 & -0.078 & 0.135 & 0.003 & 2.133 & -0.125 & 0.168 \\
\hline & \multicolumn{4}{|c|}{$\# 3$} & \multicolumn{4}{|c|}{$\# 4$} \\
\hline 50 & 0.537 & 1.973 & 0.133 & 0.074 & 0.247 & 2.178 & 0.126 & 0.113 \\
\hline 100 & 0.141 & 3.534 & 0.075 & 0.129 & 0.026 & 2.622 & 0.009 & 0.112 \\
\hline 200 & 0.006 & 2.771 & -0.032 & 0.119 & 0.008 & 2.167 & -0.063 & 0.128 \\
\hline 300 & 0.004 & 2.682 & -0.092 & 0.147 & 0.003 & 2.288 & -0.058 & 0.087 \\
\hline
\end{tabular}

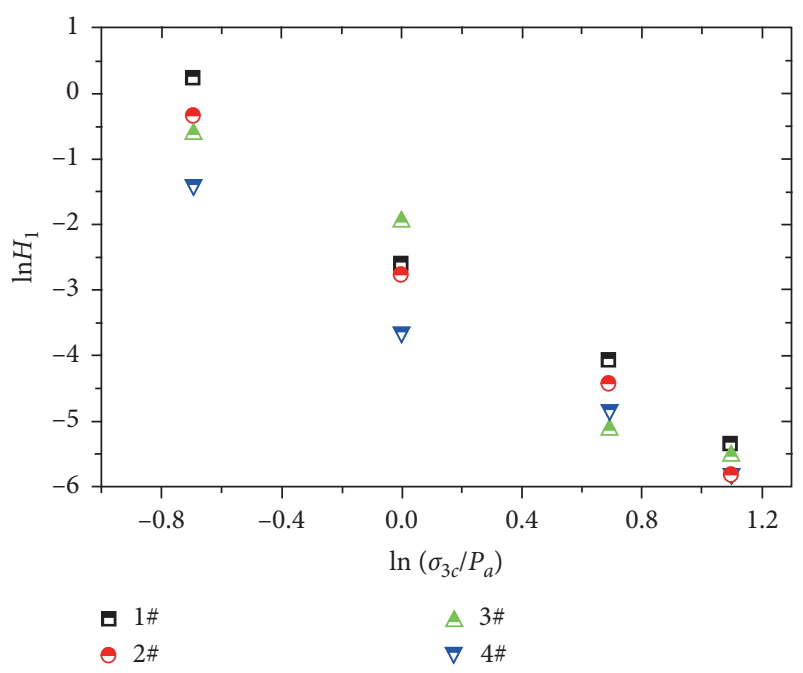

(a)

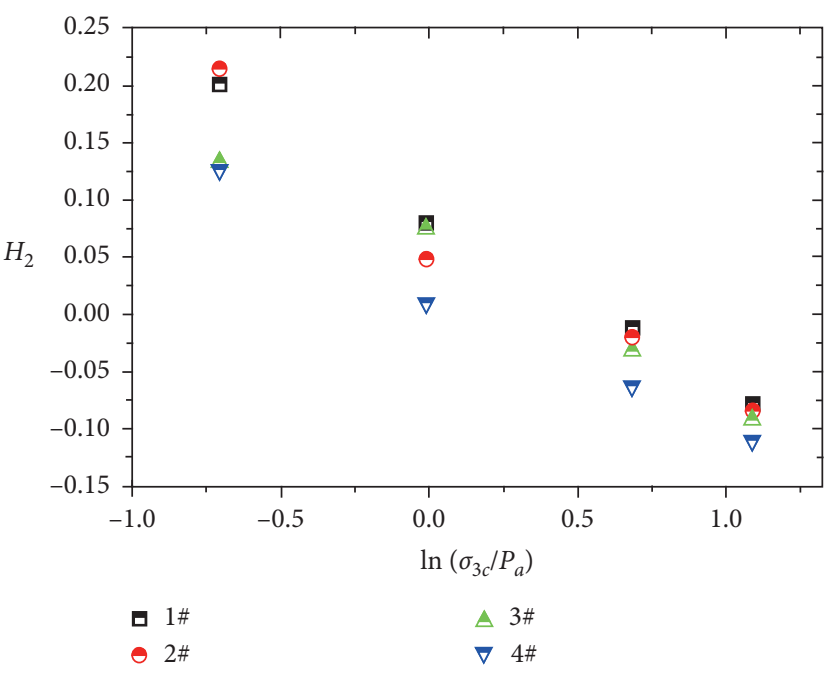

(b)

FIgURE 10: The linear relationship of $\ln \left(\sigma_{3 c} / p_{a}\right)$ and $\ln H$.

$$
\varepsilon_{v \mathrm{I}}= \begin{cases}m_{1}\left(\frac{\sigma_{3 c}}{\mathrm{p}_{a}}\right)^{\lambda_{1}}\left(\frac{p}{\mathrm{p}_{a}}\right)^{B_{1}}, & p \leq p_{y} \\ m_{2}+\lambda_{2} \ln \left(\frac{\sigma_{3 c}}{\mathrm{p}_{a}}\right)+B_{2} \ln \left(\frac{p}{\mathrm{p}_{a}}\right), & p>p_{y}\end{cases}
$$

The deviatoric stress $q_{y}$ can then be obtained from the regression model for turfy soil as follows:

$$
q_{y}=374.906+0.821 \sigma_{3 c}-2.420 F-3.617 S_{h} .
$$

The results of the model parameters are summarised in Table 7.

The deviatoric strain of turfy soil under CIAI pathways can be described as follows:
TABle 6: The calculation results of $m$ and $\lambda$.

\begin{tabular}{lcccccc}
\hline $\begin{array}{l}\text { Parameter } \\
\text { number }\end{array}$ & $m_{1}$ & $\lambda_{1}$ & $R^{2}$ & $m_{2}$ & $\lambda_{2}$ & $R^{2}$ \\
\hline$\# 1$ & 0.114 & -3.094 & 0.9739 & 0.088 & -0.154 & 0.9961 \\
$\# 2$ & 0.079 & -2.983 & 0.9922 & 0.082 & -0.160 & 0.9485 \\
$\# 3$ & 0.081 & -2.974 & 0.9395 & 0.055 & -0.129 & 0.9733 \\
$\# 4$ & 0.037 & -2.385 & 0.9713 & 0.025 & -0.129 & 0.9795 \\
\hline
\end{tabular}

$$
\varepsilon_{s I}= \begin{cases}n_{1}\left(\frac{\sigma_{3 c}}{p_{a}}\right)^{\kappa_{1}}\left(\frac{q}{p_{a}}\right)^{C_{1}}, & q \leq q_{y}, \\ n_{2}+n_{3}+\kappa_{2}\left(\frac{\sigma_{3 c}}{p_{a}}\right)+\kappa_{3}\left(\frac{\sigma_{3 c}}{p_{a}}\right) \ln \left(\frac{q}{p_{a}}\right), & q>q_{y} .\end{cases}
$$


TABLE 7: Calculation results of parameters under deviatoric stress.

\begin{tabular}{lccccccrrr}
\hline Parameter number & $n_{1}$ & $\kappa_{1}$ & $R_{1}{ }^{2}$ & $n_{2}$ & $\kappa_{2}$ & $R_{2}{ }^{2}$ & $n_{3}$ & $\kappa_{3}$ & $R_{3}{ }^{2}$ \\
\hline$\# 1$ & 0.084 & -2.244 & 0.9373 & 0.178 & -0.104 & 0.9711 & 0.096 & 0.035 & 0.9275 \\
$\# 2$ & 0.068 & -2.196 & 0.9739 & 0.172 & -0.106 & 0.9835 & 0.084 & 0.071 & 0.9024 \\
$\# 3$ & 0.108 & -2.690 & 0.9535 & 0.174 & -0.100 & 0.9263 & 0.062 & 0.043 & 0.9270 \\
$\# 4$ & 0.062 & -1.864 & 0.9855 & 0.156 & -0.097 & 0.9660 & 0.076 & 0.031 & 0.9536 \\
\hline
\end{tabular}

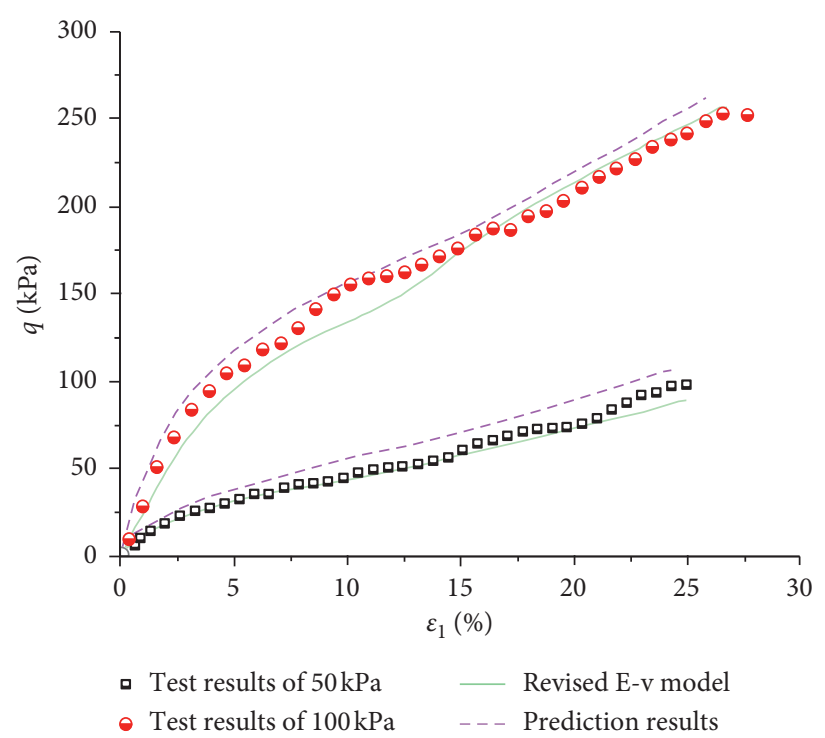

(a)

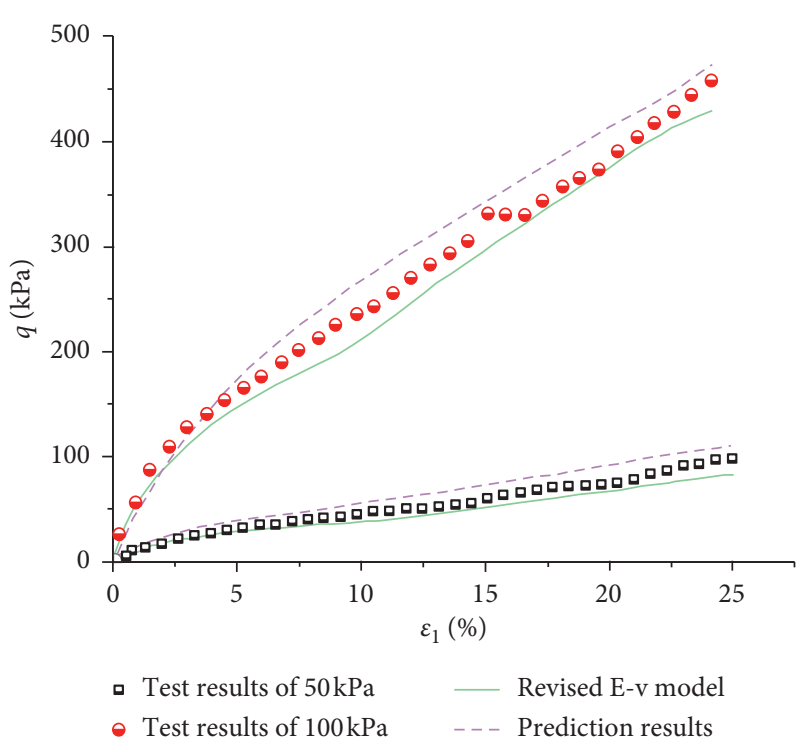

(b)

FIGURE 11: Comparison of the test results and prediction results of turfy soil.

3.2. Validation of the Constitutive Model. Two turfy soils were tested to assess the accuracy of the constitutive model. Additionally, a modified $E-v$ model was used to predict the $q-\varepsilon_{1}$ curve [37]. The experimental and prediction results are summarised in Figure 11, and the purple-dashed line shows the results predicted by the model proposed in this paper. In the elastic stage, the constitutive model's results are consistent with the experimental results, whereas the calculated strain results are slightly less than the experimental results. Overall, the predictions of the modified $E-v$ model are relatively smaller, while the predictions of the stress path constitutive model constructed in this paper are slightly larger. The constitutive model's results are consistent with the experimental results, suggesting that the stress path constitutive model constructed in this article can accurately simulate the deformation and strength characteristics of the original state of turfy soil under CIAI pathways.

\section{Conclusion}

(1) The decomposition degree and organic matter content exerted strong influences on the physical and mechanical properties, such as stress, strain, strength, and failure characteristics of the analysed turfy soils.

(2) The decomposition degree and organic matter content tests, along with drained triaxial compression tests under CIAI pathways, revealed changes in the volumetric strain and plastic deviator of the turfy soils under the CIAI pathways, thereby allowing for a constitutive model to be established.

(3) The results calculated by the constitutive model, which considers the decomposition degree and organic matter content, are similar to the experimental results, and they may provide a comprehensive representation of the original deformation state and strength characteristics of the turfy soil.

\section{Data Availability}

The settlement monitoring data used to support the findings of this study are included within the article. The partial analysis data used to support the findings of this study are available from the corresponding author upon request.

\section{Conflicts of Interest}

The authors declare that there are no conflicts of interest.

\section{Acknowledgments}

The authors are grateful for financial support from the National Natural Science Foundation of China (Grant nos. 41502272 and 41572254). The authors received funds to cover publication costs, and they also would like to 
acknowledge the testing science experiment center of Jilin University for supporting the experiment.

\section{References}

[1] Y. Lv, L. Nie, K. Xu, and D. S. Zhan, "Study on the difference between turfy soil and normal peat soil in China," Applied Mechanics and Materials, vol. 105-107, pp. 1551-1554, 2012.

[2] H. Yumin, X. Shi, G. Che, and Y. Liu, Experimental Study on the Frost Heaving Characteristics of Turfy Soil Foundation, Springer, Berlin, Germany, 2012.

[3] Y. Liu, G. Z. Cao, Y. G. Meng, and M. X. Liu, "Study on the microstructure feature and strength mechanism of the tien lake peat soil," Advanced Materials Research, vol. 864-867, pp. 2695-2702, 2013.

[4] M. Long and N. Boylan, "Predictions of settlement in peat soils," The Quarterly Journal of Engineering Geology and Hydrogeology, vol. 46, no. 3, pp. 303-322, 2013.

[5] S. Tang, L. Nie, D. Y. Qiao, Y. Lv, and X. R. Yang, "Study on the difference between multipotiential surface model and duncan-chang model based on the triaxial test of heda highway turfy soil," Advanced Materials Research, vol. 538-541, pp. 965-970, 2012.

[6] N. Boylan, P. Jennings, and M. Long, "Peat slope failure in Ireland," The Quarterly Journal of Engineering Geology and Hydrogeology, vol. 41, no. 1, pp. 93-108, 2008.

[7] A. P. Dykes and P. Jennings, "Peat slope failures and other mass movements in western Ireland, August 2008," The Quarterly Journal of Engineering Geology and Hydrogeology, vol. 44, 2011.

[8] J. H. Yin, Constitutive Modelling of Time-Dependent StressStrain Behaviour of Soils, University of Manitoba, Manitoba, Canada, 1990.

[9] J.-H. Yin, F. Saadat, and J. Graham, "Constitutive modelling of a compacted sand-bentonite mixture using three-modulus hypoelasticity," Canadian Geotechnical Journal, vol. 27, no. 3, pp. 365-372, 1990.

[10] P. Dong, Z. Wei, and J. K. Hong, "A path-dependent cycle counting method for variable-amplitude multi-axial loading," International Journal of Fatigue, vol. 32, no. 4, pp. 720-734, 2010.

[11] M. Nurcheshmeh and D. E. Green, "Forming limits for threedimensional stress states and nonlinear loading paths," in Proceedings of the 9th International Conference and Workshop on Numerical Simulation of 3D Sheet Metal Forming Processes: Part A Benchmark Problems and Results and Part B General Papers, Melbourne, Australia, December 2013.

[12] F. E. Sánchez and M. B. Aguado, "Stress-strain behaviour of the sediments in the tertiary basins associated with the Alentejo-Plasencia fault in the province of Caceres (Spain)," Bulletin of Engineering Geology and the Environment, vol. 74, no. 3, pp. 733-743, 2015.

[13] P. V. Lade and M. K. Kim, "Single hardening constitutive model for frictional materials II. Yield critirion and plastic work contours," Computers and Geotechnics, vol. 6, no. 1, pp. 13-29, 1988.

[14] L. Nie, Y. Lv, and M. Li, "Influence of organic content and degree of decomposition on the engineering properties of a peat soil in NE China," The Quarterly Journal of Engineering Geology and Hydrogeology, vol. 45, no. 4, pp. 435-446, 2012.

[15] A. Haraguchi, C. Hasegawa, A. Hirayama, and H. Kojima, "Decomposition activity of peat soils in geogenous mires in Sasakami, central Japan," European Journal of Soil Biology, vol. 39, no. 4, pp. 191-196, 2003.
[16] A. Pitkanen, H. Simola, and J. Turunen, "Dynamics of organic matter accumulation and decomposition in the surface soil of forestry-drained peatland sites in Finland," Forest Ecology \& Management, vol. 284, pp. 100-106, 2012.

[17] L. Nie, Z. Su, D. Qiao, X. Yang, and H. Zhang, "Normalized investigation of the peat soil in seasonal frozen region," Energy education science and technology, Part A. Energy science and research, vol. 31, no. 1, pp. 381-384, 2013.

[18] A. Assadi, "Quantitative evaluation of microstructure characteristics of cement-consolidated soil," Bulletin of Engineering Geology\&the Environment, vol. 73, 2014.

[19] T.-L. Yang and S.-L. Gong, "Microscopic analysis of the engineering geological behavior of soft clay in Shanghai, China," Bulletin of Engineering Geology and the Environment, vol. 69, no. 4, pp. 607-615, 2010.

[20] J. M. Duncan and C.-Y. Chang, "Nonlinear analysis of stress and strain in soils," Journal of the Soil Mechanics and Foundations Division, vol. 96, no. 5, pp. 1629-1653, 1970.

[21] J. P. Bardet, "Bounding surface plasticity model for sands," Journal of Engineering Mechanics, vol. 112, no. 11, pp. 11981217, 1986.

[22] A. Gajo and D. Bigoni, "A model for stress and plastic strain induced nonlinear, hyperelastic anisotropy in soils," International Journal for Numerical and Analytical Methods in Geomechanics, vol. 32, no. 7, pp. 833-861, 2008.

[23] D. Li, C. Zhang, and G. Ding, "Fractional derivative-based creep constitutive model of deep artificial frozen soil," Cold Regions Science and Technology, vol. 170, Article ID 102942, 2020.

[24] Y.-P. Yao, W. Hou, and A.-N. Zhou, "UH model: three-dimensional unified hardening model for overconsolidated clays," Géotechnique, vol. 59, no. 5, pp. 451-469, 2009.

[25] Y. F. Dafalias and M. T. Manzari, "A critical state two-surface plasticity model for sands," Géotechnique, vol. 47, no. 2, pp. 255-272, 2015.

[26] Y. Xiao and H. Liu, "Elastoplastic constitutive model for rockfill materials considering particle breakage," International Journal of Geomechanics, vol. 17, no. 1, 2017.

[27] Y. Xiao, Z. Sun, A. W. Stuedlein, C. Wang, Z. Wu, and Z. Zhang, "Bounding surface plasticity model for stress-strain and grain-crushing behaviors of rockfill materials," Geoscience Frontiers, vol. 11, no. 2, pp. 495-510, 2020.

[28] L. Domaschuk and P. Valliappan, "Nonlinear settlement analysis by finite element," Journal of the Geotechnical Engineering Division, vol. 101, no. 7, pp. 120-123, 1975.

[29] C. A. Anagnostopoulos and I. N. Grammatikopoulos, "A new model for the prediction of secondary compression index of soft compressible soils," Bulletin of Engineering Geology and the Environment, vol. 70, no. 3, pp. 423-427, 2011.

[30] M. Ozer, N. S. Isik, and M. Orhan, "Statistical and neural network assessment of the compression index of clay-bearing soils," Bulletin of Engineering Geology and the Environment, vol. 67, no. 4, pp. 537-545, 2008.

[31] L. Nie, Z.-D. Su, J. Xia, Y. Lv, and Z.-C. Li, "Study on mineral distribution of peat soil in northeast China," Asian Journal of Chemistry, vol. 25, no. 18, pp. 10150-10152, 2013.

[32] M. Gropius, "Numerical groundwater flow and heat transport modelling of open-loop ground source heat systems in the London chalk," The Quarterly Journal of Engineering Geology and Hydrogeology, vol. 43, no. 1, pp. 23-32, 2010.

[33] L. Hao, X. Zhao, H. De Boorder, J. Lu, Y. Zhao, and Q. Wei, "Origin of PGE depletion of Triassic magmatic $\mathrm{Cu}-\mathrm{Ni}$ sulfide 
deposits in the central-southern area of Jilin province, NE China," Ore Geology Reviews, vol. 63, 2014.

[34] S. H. Bricker and J. P. Bloomfield, "Controls on the basin-scale distribution of hydraulic conductivity of superficial deposits: a case study from the Thames Basin, UK," The Quarterly Journal of Engineering Geology and Hydrogeology, vol. 47, no. 3, pp. 223-236, 2014.

[35] A. Godio, S. Basiricò, G. B. Crosta, P. Frattini, and A. Villa, "Coupling ground-penetrating radar and flowmeter investigations for the characterization of a fissured aquifer," The Quarterly Journal of Engineering Geology and Hydrogeology, vol. 47, no. 4, pp. 351-361, 2014.

[36] F. H. Xu, Y. M. Jin, X. T. Liu, and J. W. Chen, "The climatic effect of Carex. meyeriana mire in the Changbai mountain valley," Ecology and Environment, vol. 15, no. 1, pp. 120-123, 2006.

[37] Z. Su, Study on the Constitutive Model of Marsh Turfy Soil in the East of Jilin Province Considering Stress Path, Jilin University, Changchun, China, 2015. 